\title{
Алгоритм стабилизации видеоизображения при наличии в поле зрения быстро двигающихся объектов
}

\author{
А.О. Лебедев \\ Новосибирский филиал Института физики полупроводников им. А. В. Ржанова СО РАН \\ «Конструкторско-технологический институт прикладной микроэлектроники», \\ 630090, г. Новосибирск, просп. Академика Лаврентьева, 2/1 \\ тел:+7 (952) 948-9982, эл. почта: artem leb@mail.ru
}

DOI 10.34077/RCSP2019-143

При использовании приборов видеонаблюдения, работающих в видимом и/или инфракрасном диапазоне, в нестационарных условиях возникает проблема нестабильности видеоизображения, обусловленная вибрацией платформы, например, связанной с ветровой нагрузкой. Особенно сильно этот эффект влияет на качество наблюдения и распознавания при применении длиннофокусных объективов, когда незначительные колебания камеры приводят к заметной нестабильности видеоизображения.

\section{Описание алгоритма}

В наиболее часто используемых алгоритмах стабилизации видеоизображения используется анализ корреляционной функции между опорным кадром и последующими $\mathrm{N}$ кадрами. Каждый последующий $\mathrm{N}$ й кадр смещается на заданную величину $\Delta \mathrm{x}+\Delta \mathrm{y}$ относительно опорного кадра и рассчитывается корреляционная функция, например, вида:

$$
A(\Delta x, \Delta y)=\sum_{i, j}^{W H}\left(I_{i+\Delta x, j+\Delta y}^{N}-I_{i, j}^{\text {base }}\right), \quad \Delta x, \Delta y \in \mathbf{N}(-M,+M)
$$

где $\mathrm{A}(\Delta \mathrm{x}, \Delta \mathrm{y})$ - корреляционная функция; $\Delta \mathrm{x}, \Delta \mathrm{y}$ - сдвиг $\mathrm{N}$ го кадра относительно опорного кадра в пикселях по вертикали и горизонтали, соответственно; W, H - ширина и высота кадра в пикселях,

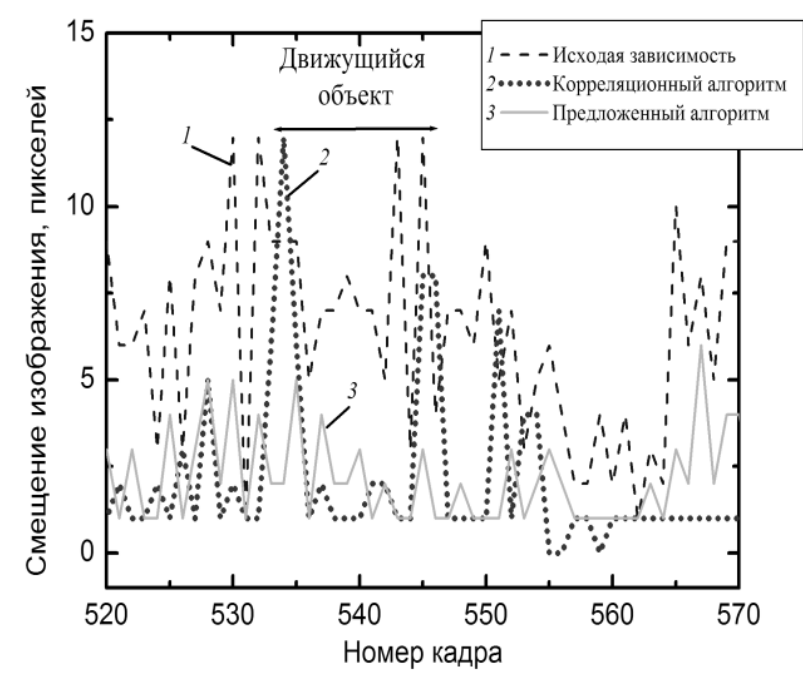
соответственно; $\mathrm{Ii}, \mathrm{j}$ - величины сигналов пикселей $\mathrm{c}$ координатами i,j; M - целая константа, соответствующая максимальному сдвигу, определяется параметрами фотоприемника и условиями наблюдения.

Для реализации алгоритма на изображении выбиралась сетка реперных точек. Далее анализ оптического потоках проводился только по этим точкам. Вычисляется среднее значение вектора смещения реперных точек $\left(\Delta \mathrm{x}_{\mathrm{cp}}+\Delta \mathrm{y}_{\mathrm{cp}}\right)$, между двумя соседними кадрами и определяются точки со смещением, больше среднего значения на заданную величину $\left(\Delta \mathrm{x}+\Delta \mathrm{y}=\Delta \mathrm{x}_{\mathrm{cp}}+\Delta \mathrm{y}_{\mathrm{cp}}+\right.$ const $)$. Если заданное число соседних реперных точек имеют величину смещения выше средней на заданную величину, то считается, что эти точки относятся к быстро двигающемуся объекту (область, связанная с движущимся грузовика, выделена прямоугольником) и исключаются из дальнейшего анализа.

В работе предложен алгоритм стабилизации видеоизображения в режиме реального времени в условиях, когда в сцене присутствует быстро двигающиеся объекты. В приборах с реконфигурируемыми вычислительными платформами возможно использование нескольких алгоритмов обработки изображения без изменения аппаратной части. Выбор алгоритма осуществляется оператором нажатием соответствующей кнопки или выбором алгоритма из меню программы. Предложенный алгоритм может использоваться в таких системах как дополнительная возможность получения стабилизированных видеоизображений в условиях, когда в поле зрения появляются двигающиеся объекты.

\section{Лumepamypa}

[1] Fabrizio La Rosa, Maria Celvisia Virzì, Filippo Bonaccorso, Marco Branciforte. Optical Image Stabilization (OIS) // STMicroelectronics [Электронный ресурс]. URL: www.st.com/resource/en/white_paper/ois_white_paper.pdf 